\title{
The prevention and treatment of venous thromboembolism with LMWHs and new anticoagulants
}

This article was published in the following Dove Press journal:

Vascular Health and Risk Management

3 September 2009

Number of times this article has been viewed

\author{
Andrew D Blann \\ Chee W Khoo \\ University Department of Medicine, \\ City Hospital, Birmingham, UK
}

\begin{abstract}
As the risk factors for thrombosis are becoming better understood, so is the need for anticoagulation. The inherent difficulties with warfarin are such that a low-molecular-weight heparin (LMWH) is often the key therapeutic. However, there are several different species of LMWH available to the practitioner, which leads to the need for an objective guide. New agents are coming onto the marketplace, and these may supersede both warfarin and the heparins. The current report will review the biochemistry and pharmacology of different LWMHs and identify which are more suitable for the different presentations of venous thromboembolism. It will conclude with a brief synopsis of new agents which may supersede warfarin and heparin.
\end{abstract}

Keywords: thrombosis, warfarin, heparin, anticoagulation

\section{Introduction}

The major common endpoint in most human disease is thrombosis and the major causes of arterial thrombosis (such as diabetes) have been established for decades. The risk factors for venous thromboembolism (VTE) (such as obesity and orthopedic surgery) are also now becoming well established and the penetrance of these factors in the pathophysiology of thrombosis is so strong that anticoagulation is often mandatory. Indeed, VTE is a frequent complication among hospital in-patients and contributes to longer hospital stays, morbidity, and mortality. ${ }^{1-4}$ Some VTEs may be subclinical and patients presenting with sudden pulmonary embolus (PE) or deep vein thrombosis (DVT) are common in acute medicine. Using ultrasonic Doppler and venographic techniques, DVT of the lower limb has been documented in half of all major lower limb orthopedic operations performed without antithrombotic prophylaxis, a quarter of patients with acute myocardial infarction (MI) and more than half of patients with acute ischemic stroke. Indeed, some risk factors are more likely to evoke a VTE than others (Table 1).

Accordingly, anticoagulation is demanded. However, the perfect anticoagulant (rapid mode of action and cessation, oral availability, minimal side effects, etc) does not exist. Instead, we have a crude poison with a long time to action and long half-life with a wide range of effect in different patients leading to difficulties in management (that is, warfarin), and an injectable agent with poor pharmacokinetics such that regular blood testing is required, and a risk of thrombocytopenia (that is, heparin). ${ }^{5}$ More recently, some of the disadvantages of heparin have been reduced with the introduction of an improved preparation: low-molecular-weight heparin (LMWH). ${ }^{6,7}$
Correspondence: Andrew D Blann, PhD, FRCPath

University Department of Medicine, City Hospital, Birmingham BI8 7QH, UK Tel +44 I2I 5075076

Fax +44 I2I 5075076

Email a.blann@bham.ac.uk 
Table I Stratification of the risk factor for VTE

Strong risk factors (increased risk $>10$ )

Hip, pelvis or leg fracture, hip or knee replacement, major general surgery (eg, CABG), major trauma, spinal cord injury, hospital or nursing home confinement

Moderate risk factors (increased risk 2-9)

Arthroscopic knee surgery, central venous lines, malignancy (alone, 2-4 times, But with chemotherapy this rises to 4-6 times), congestive heart or respiratory failure, HRT, use of oral contraceptives, paralytic stroke, post-partum pregnancy, previous VTE, thrombophilia, neurological disease with extremity paresis, varicose veins at age 45 , superficial vein thrombosis

Weak risk factors (increased risk $<2$ )

Bed rest $>3$ days, immobility due to sitting (eg, prolonged car or air travel, wheelchair), increasing age, laparoscopic surgery (eg, cholecystectomy), obesity, ante-partum pregnancy, varicose veins at age 60

Abbreviations: CABG, coronary artery bypass graft; HRT, hormone replacement therapy; VTE, venous thromboembolism.

However, there are several different species of LMWH available for the prevention of VTE, and all have slightly different properties and licenses for different risk situations. Fortunately, new anticoagulants are coming on to the market and it is conceivable that they will slowly take over from both warfarin and the heparins over the coming decade.

The objective of this communication is to review the role of the different LMWHs in the prevention of VTE. In order to do this the position of (unfractionated) heparin will be first be reviewed, following by an in-depth examination of LMWH. It will conclude with an examination of new anticoagulants.

\section{Heparin}

The modern era of heparin can be traced to 1880 with the description of anticoagulant preparations that evolved into heparin $^{8-11}$ that ultimately became clinically useful. ${ }^{12-14}$ Brinkhous and colleagues ${ }^{15}$ subsequently demonstrated the requirement of heparin for another substance in order for anticoagulation to be effected, a factor that we now recognize as antithrombin (formerly antithrombin III). Commercial heparin was thus ready for industrial/pharmacological scale production. By 1979, its value in prophylaxis for venous thrombosis, $\mathrm{PE}$, and other possible problems were established. ${ }^{5}$ The laboratory potential of a more efficacious fraction of whole, unfractionated heparin, ie, LMWH, was recognized in $1979^{16,17}$ and clinical note was made shortly afterwards. ${ }^{18,19}$

\section{Mode of action}

Heparin is a natural product present on the cell membrane, but when provided as a therapeutic drug, it is a mixture of glycosaminoglycans and polysaccharides composed of long chains of repeated disaccharide units (hexosamine and glucuronic or iduronic acid), although the composition of different macromolecules vary markedly. In its whole, unfractionated form, with species of molecular weights ranging from 3 to $30 \mathrm{kDa}$ (although most is in the range $12-15 \mathrm{kDa}$ ), perhaps only one-third of a standard heparin preparation has anticoagulant activity. ${ }^{5}$ Heparin by itself is not an anticoagulant: it is a co-factor in the activity of antithrombin, a $58 \mathrm{kDa}$ single chain polypeptide synthesized in the liver. ${ }^{20}$

Heparin binding to specific sites on antithrombin induces a conformational change in the latter, exposing a site that binds serine proteases factor Xa, thrombin (IIa) (in approximately equal proportions) and, with less affinity, factors IXa, XIa, XIIa, kallikrein, plasmin, and $\mathrm{C}_{1}$-esterase, although almost all of its effects are against thrombin and factor $\mathrm{Xa}^{5}$ However, heparin fractions less than 18 monosaccharide units (3-4 kDa) do not enhance the inhibition of thrombin by antithrombin and probably act via factor Xa inhibition. The major inhibitor of coagulation, the effects of antithrombin are accelerated some 1000-fold in the presence of heparin. It follows, therefore, that special measures are required in subjects deficient in antithrombin (whether by genetics or excess consumption). In high doses, heparin also prolongs the bleeding time by inhibiting platelet aggregation in vitro ${ }^{21}$ and may exert some effect on the endothelium, ${ }^{22}$ although it is unclear (and possibly academic) whether or not these influence clinical efficacy.

\section{Clinical effectiveness}

Due to variability of effect in different individuals, mostly due to complex pharmacokinetics (such as degree of binding to numerous proteins including, platelet factor 4 , vitronectin, fibronectin and von Willebrand factor), ${ }^{23,24}$ laboratory monitoring of the effects of heparin is necessary and can be followed with the relatively straightforward activated partial thromboplastin time (APTT), thrombin time, and to lesser extent, the prothrombin time. The APTT derives from the ability 
of citrated plasma to clot an artificial 'platelet' substitute of phospholipids and other substances to which calcium has to be added: quality control is crucial as the quality of reagents can vary markedly. ${ }^{25}$ In practice, most clinicians aim for a degree of anticoagulation that prolongs the APTT by anything from 1.5 to 3 times that of normal, uncoagulated blood, ie, an APTT patient/control ratio of 1.5:3.0.4,26

The primary use of heparin has been, and continues to be, in the treatment and prophylaxis of VTE. ${ }^{5,26,27}$ As with aspirin, early crucial work was performed in the 1960's with studies looking at the effect of heparin on PE and DVT. ${ }^{28,29}$ However, heparin is not absorbed from the gastrointestinal tract and so must be given intravenously or subcutaneously, with the former providing a more rapid effect. Subsequent trials not only confirmed the efficacy of this agent, but also showed that continuous intravenous infusion was frequently preferable to subcutaneous or intermittent infusions. ${ }^{30,31}$ One 'typical' trial reported a frequency of asymptomatic extension of DVT or PE of $8.2 \%$ of patients with proximal DVT taking heparin and oral anticoagulation compared to a frequency of $39.6 \%$ in those taking oral anticoagulants alone. ${ }^{32}$ There was also a reduction in the report of symptomatic events $(6.7 \%$ versus $20 \%)$, but no difference in hemorrhagic complication $(3 \%$ versus 5\%). In practice, until recently, hospital treatment of, and prophylaxis against, VTE, generally began with heparin, moving oral anticoagulants following discharge, for varying periods up to six months. ${ }^{33}$

\section{Clinical side effects}

As with aspirin, the major problem with heparin is in dosedependent excess bleeding. Early commentaries reported a rate of hemorrhagic complications of up to $30 \%$. ${ }^{34}$ However, a later review reported an incidence of $6.8 \%$ in patients given continuous infusion and $14.2 \%$ in patients given intermittent intravenous injections, ${ }^{5}$ emphasizing four important variables: dose, patient's anticoagulant response, method of administration, and other patient-related factors such as renal failure or chronic alcohol use. Gallus and colleagues ${ }^{35}$ reported an incidence of major bleeding of $11 \%$ in high-risk patients, compared to $1 \%$ in low-risk patients.

Surprisingly, heparin-induced thrombocytopenia (HIT; generally platelet count $<140,000$ cells $/ \mu \mathrm{L}$, and reversible) has been described for 50 years, ${ }^{36}$ with two forms (nonimmune and immune [often an immunoglobulin $\mathrm{G}$ [IgG] targeting a heparin/platelet factor 4 complex]) being recognized. ${ }^{37}$ When the platelet count falls, especially if it falls from normal to less than $<100,000$ cells $/ \mu \mathrm{L}$, cessation is mandatory and alternate anticoagulant cover (eg, argatroban $)^{26,38}$ is necessary. Curiously, $0.4 \%$ of patients with HIT suffer arterial thrombosis (that may follow platelet aggregation in vivo) or venous thrombosis (that may result from heparin resistance caused by the neutralizing effect of the heparin-induced release of platelet factor 4). These events may be related to the generation of thrombin, ${ }^{39}$ and also to platelet activation by heparin..$^{21,40}$ If present, HIT is likely to be apparent 3 to 15 days after initiation (such that a platelet count is advised on days 3-5), but may also occur very rarely within hours, with the platelet count returning to normal within four days of discontinuation. ${ }^{41}$ Rates of HIT vary between $<0.1 \%$ and $3 \% .^{26,37,42}$

Other uncommon side effects of heparin (especially in long-term and high-dose use) include fractures and osteopenia, hyperkalemia, elevations in liver enzymes, skin necrosis at the site of administration, alopecia, hypersensitivity, priapism, and hypoaldosteronism.,26,43-48 Thus, despite the proven safety and effectiveness of continuous infusions of heparin, its limitations and adverse side effect profile, unpredictable pharmacokinetic response, daily laboratory monitoring with dose adjustments, and requirement for hospitalization leaves room for alternatives. One such alternative is a low-molecular-weight variant of the standard (unfractionated) heparin preparation.

\section{Low-molecular-weight heparin}

The laboratory demonstration of a more efficacious fraction of whole, unfractionated heparin, ie, LMWH, ${ }^{16-19}$ has ushered in a new era of anticoagulation. LMWH can be manufactured from unfractionated heparin by diverse routes, such as benzylation with alkaline hydrolysis, nitrous acid depolymerization or digestion, heparinase digestion, and isoamyl nitrate digestion. Each provides a different LMWH with mean molecular weights varying from $4371 \mathrm{Da}$ to $5866 \mathrm{Da}$, so that each has different pharmacokinetics and activities. ${ }^{49-51}$ However, there are common class advantages over unfractionated heparin (Table 2), most of which address mode of action and side effects. Broadly speaking, compared to unfractionated heparin, LMWH has a longer subcutaneous half-life and therefore has potential for outpatient use, a more predictable anticoagulant response requiring less monitoring, and has better antifactor Xa effect.

Building on early trials, ${ }^{18,19}$ several large studies have unequivocally demonstrated the value of LMWH in the initial treatment of DVT. ${ }^{52-54}$ Lensing and colleagues ${ }^{52}$ described a recurrence rate of $3.1 \%$ in patients on LWMH compared to $6.6 \%(\mathrm{p}<0.01)$ in those on standard heparin, with $0.8 \%$ and $2.8 \%(\mathrm{p}<0.005)$ suffering a major bleed, respectively, 
Table 2 Differences between low-molecular-weight heparin and unfractionated heparin ${ }^{48-51}$

\begin{tabular}{lll}
\hline & $\begin{array}{l}\text { Low-molecular- } \\
\text { weight heparin }\end{array}$ & $\begin{array}{l}\text { Unfractionated } \\
\text { heparin }\end{array}$ \\
\hline Mean molecular weight (kDa) & 5 & 15 \\
Saccharide units & I3-22 & $40-50$ \\
Anti-Xa/Anti-lla activity & $2: 1$ to 4:I & I:I \\
Platelet inhibition & ++ & ++++ \\
Inhibited by PF4 & No & Yes \\
Bioavailability & $92 \%-100 \%$ & $30 \%-50 \%$ \\
Half-life (hours) & & \\
$\quad$ Intravenous & 2 & I \\
Subcutaneous & 4 & 2 \\
Endothelial binding & No & Yes \\
Dose-dependent clearance & No & Yes \\
Mode of clearance & Kidney & Liver/kidney \\
Frequency of HIT & Low (eg, 0\%*) & High (eg, 2.7\% ${ }^{42}$ ) \\
Frequency of osteoporosis & Low & High \\
Monitoring & Anti-Xa assay & Routine APTT \\
\hline
\end{tabular}

Abbreviations: HIT, heparin-induced thrombocytopenia; PF4, platelet factor 4; APTT, activated partial thromboplastin time.

which was confirmed by other analyses. However, later trials $^{55,56}$ failed to find a difference in efficacy between the two types of heparin with equivalence of adverse events. Interestingly, these meta-analyses also reported a lower mortality with LWMH due to causes unrelated to VTE in the patients particularly with cancer. A subsequent more formal meta-analysis of 629 cancer patients did indeed demonstrate a benefit in three-month mortality for LMWH versus unfractionated heparin. ${ }^{57}$ While this is an unsought for endpoint and therefore of questionable value, there is nevertheless good mechanistic evidence for this benefit. ${ }^{58}$ The value of LMWH compared to unfractionated heparin now extends to prevention of thrombosis in general surgery, orthopedic surgery, hip fracture, multiple trauma, and neurosurgery, ${ }^{51}$ whilst efficacy and safety issues in medical patients have been addressed..$^{59}$

Apart from its clinical effectiveness and better side effect profile, a further advantage of LMWH is in home use by appropriate patients with DVT who are not severely ill. ${ }^{60,61}$ In both studies, LMWH administered subcutaneously twicedaily was compared with standard continuous infusion in hospital. Both reported no significant difference in recurrence of thromboembolism with similar rates of bleeding. Those on LMWH in the study of Levine and colleagues ${ }^{60}$ remained in hospital for a mean of 1.1 days, suffering 13 embolic events, compared to 6.5 days for those on unfractionated heparin, with 17 events, of which two were fatal. The health economics of these figures is apparent, even after adjustment for the higher costs of the LMWH. The study of Koopman and colleagues $^{61}$ included quality of life data: overall, there was no difference between the LMWH and unfractionated heparin groups, but those on LMWH reported better physical activity and social functioning at weeks 1-2. Data demonstrating the superiority of LMWH compared to unfractionated heparin (eg, shorter time to effective anticoagulation and more days of effective anticoagulation) continues to be published. ${ }^{62}$

Whilst the weight of literature focuses on (unprovoked) DVT and PE, LMWH is also effective in those with conditions predisposing to VTE, such as cancer, ${ }^{63-65}$ although more data on other groups, such as the obese and those in renal failure or with thrombophilia ${ }^{66-69}$ is needed and these are slowly becoming available. However, despite the weight of literature on LMWH, questions and doubts remain. For example, Knight and colleagues conclude that heparins may, in some circumstances, be pro-thrombotic. ${ }^{70}$ Thus there remains scope for more efficacious, yet safe, anticoagulants. ${ }^{71}$

\section{Which LMWHs are available?}

In the United Kingdom, pharmaceutical practice in NHS hospitals is dominated by the British National Formulary (BNF). ${ }^{72}$ This book, also available online, is updated each six months, and lists all government-approved pharmaceutical agents and their licensed indications. It follows that doses and guidelines may differ in other countries, and that doses in prefilled syringes may also differ. Four types of LMWH are described In issue 57 of the BNF. These are (in alphabetic order) bemiparin, dalteparin, enoxaparin, and tinzaparin. All are given subcutaneously and regimes are markedly different for prophylaxis of VTE versus treatment of VTE. Furthermore, all have numerous cautions and contraindications. Principal among these is the need to refer to renal function because several agents are cleared by this organ so that defective clearance effectively leads to higher biologically active levels and thus a risk of overanticoagulation, which may lead to hemorrhage. An additional concern is the liver, as failure of this organ to synthesize key coagulation proteins may also lead to a risk of hemorrhage. Other LMWHs are available and include nadroparin and certoparin.

\section{Bemiparin}

This agent is licensed for the prophylaxis of DVT. For patients at moderate risk (for the definition of risk, see Tables 4 and 5 and the discussion to come), the recommended dose is 2500 units two hours before or six hours after surgery, 
then 2500 units every 24 hours for 7-10 days. High-risk patients should receive 3500 units two hours before to six hours after surgery, then 3500 units every 24 hours for 7-10 days. Treatment of DVT (with or without PE) is likely to be 115 units/kg every 24 hours for 5-9 days and until adequate oral anticoagulation (inevitably warfarin) is established.

\section{Dalteparin}

This agent is licensed for additional indications. For prophylaxis of DVT in surgical patients at moderate risk, 2500 units 1-2 hours are given before surgery, then 2500 units every 24 hours for 5-7 days or longer. High-risk patients are also likely to require 2500 units 1-2 hours before surgery, but then 2500 units 8-12 hours later (or 5000 units on the evening before surgery, then 5000 units on the following evening), with 5000 units every 24 hours for 5-7 days or longer (five weeks in hip replacement). For prophylaxis of DVT in medical patients, 5000 units are given every 24 hours. Treatment of DVT and PE in adults is dose-adjusted to body weight less than $46 \mathrm{~kg}$, 7500 units/day, $46-56 \mathrm{~kg}$ 10,000 units/day, $57-68 \mathrm{~kg}, 12,500$ units/day, 69-82 kg, 15,000 units/day, and body weight over $83 \mathrm{~kg} 18,000$ units/day, with oral anticoagulant until the international normalized ratio (INR) is in the therapeutic range (which may take up to seven days). Monitoring of the effect of the LMWH is not usually needed but if so is by antifactor Xa assay.

There is an unlicensed indication for dalteparin for the treatment of VTE in pregnancy. This calls for dose-adjusted injections based on early pregnancy body weight: under $50 \mathrm{~kg}, 5000$ units twice daily; 50-70 kg, 6000 units twice daily; 70-90 kg 8000 units twice daily, and body weight over $90 \mathrm{~kg}, 10,000$ units twice daily. If called for, blood should be taken for monitoring 3-4 hours after a dose, and ideally the result will be in the range or 0.5 to $1 \mathrm{unit} / \mathrm{mL}$ of antifactor $\mathrm{Xa}$ activity. Monitoring is generally not required for oncedaily treatments. Notably, this desired range is higher than that for prophylaxis of a VTE, which is $0.1-0.3$ antifactor Xa units $/ \mathrm{mL}$. Dalteparin is also licensed for use in acute coronary syndromes, which are effectively unstable coronary artery disease of ST and non-ST elevation MI. The weightadjusted dose is 120 units/kg every 12 hours (up to 10,000 units twice daily) for up to eight days. Beyond this period, such as if awaiting invasive procedures, then the dose may change. Dose also varies by sex. For women weighing less than $80 \mathrm{~kg}$ and men less than $70 \mathrm{~kg}$, the recommended dose is 5000 units every 12 hours. Above this weight the dose is 7500 units every 12 hours. This proceeds until the day of the procedure for a maximum of 45 days.

\section{Enoxaparin}

This agent also has multiple indications. For prophylaxis of DVT in surgical patients at moderate risk, the recommended dose is $20 \mathrm{mg}$ (2000 units) about two hours before surgery then $20 \mathrm{mg}$ (2000 units) every 24 hours. High-risk patients (such as those undergoing orthopedic surgery) will need $40 \mathrm{mg}$ (4000 units) 12 hours before surgery and repeated every 24 hours for 7-10 days. Medical patients have the same regime but for at least six days and until ambulant to a maximum of 14 days. Treatment of either forms of VTE calls for $1.5 \mathrm{mg} / \mathrm{kg}$ (150 units $/ \mathrm{kg}$ ) every 24 hours, usually for at least five days and until oral anticoagulation is effective (generally INR 2-3). In unstable angina and non-ST-segment elevation MI, $1 \mathrm{mg} / \mathrm{kg}$ (100 units $/ \mathrm{kg}$ ) every 12 hours usually for 2-8 days (minimum two days) is recommended, and there is also an unlicensed indication for the treatment of VTE in pregnancy: early pregnancy body weight under $50 \mathrm{~kg}, 40 \mathrm{mg}$ (4000 units) twice daily; body weight $50-70 \mathrm{~kg}$, $60 \mathrm{mg}$ (6000 units) twice daily; body weight 70-90 kg, $80 \mathrm{mg}$ (8000 units) twice daily; body weight over $90 \mathrm{~kg}, 100 \mathrm{mg}$ (10 000 units) twice daily.

\section{Tinzaparin}

For the prophylaxis of DVT in general surgery, the recommended dose is 3500 units two hours before surgery, then 3500 units every 24 hours for 7-10 days. In orthopedic surgery, it may be dose-adjusted: 50 units/kg two hours before surgery, then 50 units/kg every 24 hours for 7-10 days or 4500 units 12 hours before surgery, then 4500 units every 24 hours for 7-10 days. The treatment of DVT and PE calls for 175 units/kg once daily for at least six days and until adequate oral anticoagulation, eg, with warfarin, is established. Once more, there is an unlicensed indication of VTE in pregnancy, which is 175 units $/ \mathrm{kg}$ once daily.

\section{Choice of LMWH}

The previous section listed the different clinical scenarios that each LMWH may be used for. Leaving aside economic considerations, the practical level issues of ease of prescribing, dose adjustment, and timing of dose seem relevant. The practitioner must also be fully aware of cautions, contraindications, and other caveats of each particular LMWH which may be relevant in a particular patient. Irritatingly, there are few (if any) good, well powered trials comparing one LMWH with another. In almost all such trials the (generally inferior) comparator is unfractionated heparin. ${ }^{52-59}$ All other factors being equal, due to pressures on individual hospital pharmacies, many opt for a LMWH that has the broadest range of clinical applications (Table 3 ). 
Table 3 Indication for the use of low-molecular-weight heparins

\begin{tabular}{|c|c|c|c|c|}
\hline & Bemiparin & Dalteparin & Enoxaparin & Tinzaparin \\
\hline Prophylaxis of VTE & Yes & Yes & Yes & Yes \\
\hline Treatment of VTE & Yes & Yes & Yes & Yes \\
\hline $\begin{array}{l}\text { Treatment of VTE in pregnancy } \\
\text { (unlicensed) }\end{array}$ & No & Yes & Yes & Yes \\
\hline $\begin{array}{l}\text { Prophylaxis of VTE in acute } \\
\text { coronary syndromes }\end{array}$ & No & Yes & Yes & No \\
\hline
\end{tabular}

Notes: Data was obtained from BNF. ${ }^{72}$ Referral in practice is essential, especially in view of cautions and contraindications which may be low-molecular-weight heparin-specific.

\section{Use of LMWHs in practice}

Fortunately, there are numerous guidelines for the use of LMWHs for prophylaxis in various settings such as in obstetrics and gynecology, and after surgery, and many are available free and online. ${ }^{73-79}$ Practice in surgery in the UK is dominated by guidelines from the National Institute for Health and Clinical Excellent (NICE). ${ }^{79}$ However, other comprehensive guidelines with more international appeal such as those of the American College of Chest Physicians ${ }^{73}$ are widely used. Unsurprisingly, there is often considerable agreement between these guidelines. The NICE document recommends that all patients about to undergo surgery should be assessed to identify their risk factors for developing VTE, which can be assessed by a scoring system. Once a particular patient's risk of VTE has been assessed (Table 4), then the risk afforded by their surgery must also be assessed (Table 5). Clearly, some operations are more likely to promote VTE than other, and the most risky include orthopedic surgery. Once any cautions and contraindications have been addressed (such as allergy, HIT, hepatic or renal impairment), then treatment may be given (Table 6). The duration of treatment varies, bearing in mind that some patients may transfer to warfarin, especially if they have concurrent long-standing risk factors such as cancer. Notably, NICE recommends treatment for four weeks after certain orthopedic procedures. ${ }^{79}$ The section above applies to the prevention of a VTE. However, once a patient actually has a DVT or PE, then a different dosing regime is called for, which is effectively more anticoagulants (Table 7).

\section{Fondaparinux}

Technically, this agent may not be a 'heparin' or even a 'LMWH', but it certainly does inhibit the coagulation pathway in the same manner. Marketed as Arixtra $^{\circledR}$ by GlaxoSmithKline, fondaparinux is a novel, selective and reversible Xa-inhibitor, although based on the structure of heparin, is different from both heparin and LMWH. Accordingly, unlike heparin and LMWH, it has minimal, if any, activity against thrombin. ${ }^{80,81}$ Pharmacokinetics are characterized by a $100 \%$ bioavailability by subcutaneous route, lack of biometabolism, urinary excretion and a relatively long plasma half-life of 14-21 hours which permits once-daily injection. There is a rapid onset of action, with a peak activity reached in two hours. No interactions with aspirin, warfarin, or digitoxin have been noted. Fondaparinux, like LMWHs, does not affect the prothrombin

Table 4 Risk factors forVTE

\begin{tabular}{lll}
\hline Risk factors (Score I) & Risk factors (Score 2) & Risk factors (Score 3) \\
\hline Age $>60$ & Estrogen-containing pill & Immobile (>72 hours) \\
Obesity (BMI $>30)$ & HRT & History of DVT/PE \\
IHD, CCF or previous stroke & Known thrombophilic conditions & \\
Significant COPD & Malignancy & Sepsis \\
Extensive varicose veins & Known family history in two relatives & (at least one first degree) \\
Inflammatory bowel disease & Post-partum & \\
Nephrotic syndrome & Pregnancy & \\
Myeloproliferative disorders &
\end{tabular}

Abbreviations: $\mathrm{BMI}$, body mass index; $\mathrm{COPD}$, chronic obstructive pulmonary disease; $\mathrm{CCF}$, congestive cardiac failure; $\mathrm{DVT}$, deep vein thrombosis; $\mathrm{HRT}$, hormone replacement therapy; IHD, ischemic heart disease; PE, pulmonary embolism. 
Table 5 Additional risk factors for surgical inpatients

\begin{tabular}{ll}
\hline Score & Surgical procedure \\
\hline 4 & Major trauma; eg, lower limb fractures \\
4 & Major joint replacement \\
4 & Surgery for fractured neck of femur \\
3 & $\begin{array}{l}\text { Thoracotomy or abdominal surgery involving mid-line } \\
\text { laparotomy }\end{array}$ \\
3 & Total abdominal hysterectomy; including laparoscopic assisted \\
2 & Intraperitoneal laparoscopic surgery lasting $>30$ minutes \\
2 & Vascular surgery (not intra abdominal) \\
\hline & Surgery lasting $>30$ minutes \\
0 & Surgery lasting $<30$ minutes \\
\hline
\end{tabular}

Note: The total risk score will give an initial guide to therapy, although low-molecularweight heparin may not be appropriate for all patients.

time (PT) and has very weak effects on APPT but its activity can be determined by specific anti-Xa assays, if necessary. Thrombocytopenia (platelet count $<100 \times 10^{9} / \mathrm{L}$ ) occurs even less commonly than with LMWH.

Use of fondaparinux has been approved by NICE as an alternative to LMWH in certain types of surgery, such as orthopedic. ${ }^{79}$ In this setting the prophylaxis regime recommended by the $\mathrm{BNF}^{72}$ calls for $2.5 \mathrm{mg}$ six hours before surgery then $2.5 \mathrm{mg}$ daily for 5-9 days (longer after hip surgery), and the same dose for thromboprophylaxis in medical patients usually for 6-19 days. For treatment of VTE, the recommended weight-adjusted dose is $5 \mathrm{mg}$ (if weight under $50 \mathrm{~kg}$ ), $7.5 \mathrm{mg}(50-100 \mathrm{~kg}$ ), or $10 \mathrm{mg}$ (over $100 \mathrm{~kg}$ ) every 24 hours and generally for five days and until oral anticoagulation is adequate.

\section{New anticoagulants}

Although LMWHs are very effective agents, they still carry some problems such as a residual risk of heparin-induced thrombocytopenia and reliance of parenteral introduction. These, and other problems, are being overcome with the introduction of new agents. Some operate directly against thrombin, others target coagulation factor Xa. ${ }^{82-86}$

\section{Direct thrombin inhibitors}

Dabigatran etexilate (marketed as Pradaxa ${ }^{\circledR}$ by Boehringer Ingelheim $\mathrm{GmbH}$ ) is the first in a new class of anticoagulant that works by directly inhibiting thrombin. It possesses various qualities which make it potentially an attractive and promising novel oral anticoagulant with its predictable pharmacokinetics and pharmacodynamics. ${ }^{87}$ The drug has rapid absorption (within two hours) and distribution with estimated half-lives of 8-10 hours and 14-17 hours for single and multiple dose administrations, respectively. Nearly $80 \%$ of dabigatran etexilate is excreted unchanged by the kidneys with average bioavailability of $6.5 \%$, hence high doses are required to maintain adequate plasma concentrations. Of note, the drug absorption is reduced by $20 \%-25 \%$ if patients are concurrently on proton pump inhibitors. Phase II and III clinical trials have been conducted assessing dosages, efficacy, and tolerability in numerous indications such as prevention of secondary VTE, DVT, stroke, and embolism due to atrial fibrillation (AF) ${ }^{88-93}$

In the BISTRO I study ${ }^{88}$ dabigatran etexilate demonstrated an acceptable safety therapeutic profile with doses ranging between $12.5 \mathrm{mg}$ and $300 \mathrm{mg}$ twice daily in patients undergoing elective total hip replacement. Historically, the latter is one type of surgery where more than $50 \%$ of patients develop VTE in the absence of thromboprophylaxis. Subsequently, the BISTRO II study ${ }^{89}$ compared four different doses of dabigatran etexilate with enoxaparin, with a significant reduction of VTE events in total hip or knee replacement patients receiving $150 \mathrm{mg}$ twice daily, $300 \mathrm{mg}$ once daily, and $225 \mathrm{mg}$ twice daily. There is also data on stroke prevention in AF. The PETRO study ${ }^{90}$ was conducted in 502 participants randomized to receive different doses of dabigatran alone or in combination with aspirin $(81 \mathrm{mg}$ or $325 \mathrm{mg}$ ) or open-label warfarin. This clinical study found no serious liver toxicity with only a small fraction of patients $(0.9 \%)$ observed to have raised aminotransferase levels and also justified dose selection for subsequent trials.

In March 2008, the regulatory authorities of the European Union approved the use of dabigatran etexilate for DVT

Table 6 Application of risk assessment for the use of low-molecular-weight heparin (LMWH)

\begin{tabular}{lll}
\hline Low risk Score $\mathbf{0}$ or $\mathbf{I}$ & Moderate risk Score $\mathbf{2}$ or $\mathbf{3}$ & High risk Score $\geq \mathbf{4}$ \\
\hline - Early ambulation & - GECS & - GECS \\
- Consider GECS & - Low dose LMWH od for surgical patients & - High dose LMWH od (max. I4 days for medical inpatients) \\
& - High dose LMWH od for medical patients & - Surgical patients - consider IPC in theatre plus high dose LMWH \\
\hline
\end{tabular}

Note: For male patients $<57 \mathrm{~kg}$ and female patients $<45 \mathrm{~kg}$, caution may be needed regarding the dose of LMWH prescribed.

Abbreviations: IPC, intermittent pneumatic compression; GECS, graduated elastic compression stockings; od, once daily. 
Table 7 Use of low-molecular-weight heparins in prophylaxis versus treatment in an $80 \mathrm{~kg}$ patient

\begin{tabular}{|c|c|c|c|c|}
\hline & Bemiparin & Dalteparin & Enoxaparin & Tinzaparin \\
\hline $\begin{array}{l}\text { Prophylaxis in } \\
\text { moderate-risk surgery }\end{array}$ & 2500 units & 2500 units & $20 \mathrm{mg} / 2000$ units & $\begin{array}{l}3500 \text { units } \\
\text { (general surgery) }\end{array}$ \\
\hline $\begin{array}{l}\text { Prophylaxis in } \\
\text { high-risk surgery }\end{array}$ & 3500 units & 5000 units & $40 \mathrm{mg} / 4000$ units & $\begin{array}{l}4000-4500 \text { units } \\
\text { (orthopedic surgery) }\end{array}$ \\
\hline Treatment of VTE & 9200 units & I5000 units & $120 \mathrm{mg} / \mathrm{I} 2000$ units & I 4000 units \\
\hline
\end{tabular}

Notes: Data obtained from BNF.72 Practitioners must consult this source or their own local guidelines before acting.

prevention postelective total hip or knee replacement surgery. This was followed by approvals from Health Canada in June 2008. Dabigatran etexilate has been available in UK since April 2008 and was subsequently included in the DVT prevention guidance issued by NICE five months later., ${ }^{94,95}$ The BNF recommended daily doses for VTE prevention in total knee replacement surgery is $110 \mathrm{mg}$ (elderly over 75 years, $75 \mathrm{mg}$ ) $1-4$ hours after surgery, then $220 \mathrm{mg}$ daily (elderly over $75,150 \mathrm{mg}$ ) for nine days. For total hip replacement surgery, the same dose is recommended but it should continue for 27-34 days. As is common practice with almost all anticoagulants, patients with moderate renal impairment (glomerular filtration rate $30-50 \mathrm{~mL} / \mathrm{min}$ ) require reduced dosages.

\section{Factor Xa inhibitors}

These agents reversibly block free factor Xa and that factor $\mathrm{Xa}$ that is bound to platelets within the prothrombinase complex. Two oral factor Xa inhibitors are currently under various stages of clinical development and are close to potential clinical application. Rivaroxaban (marketed as Xarelto ${ }^{\circledR}$ by Bayer Schering Pharma AG) is the first selective oral direct factor Xa inhibitor advanced to phase III clinical trials. It has favorable pharmacokinetic characteristics with a bioavailability of $60 \%-80 \%$. Rivaroxaban achieves peak plasma levels in three hours and has a half-life of nine hours in healthy, young subjects and about 12 hours in elderly subjects. However, the drug has been tested for clinical use only on a once-daily basis. Rivaroxaban is metabolized by the liver via CYP3A4 with up to two-thirds of the drug being eliminated by the kidneys. The use of rivaroxaban in patients with renal impairment has to be cautious because of its renal clearance. It does not significantly interact with platelet function in preclinical studies, where it demonstrated an excellent correlation between its plasma levels and achieved clotting times, while the bleeding risk was comparable to that of enoxaparin. ${ }^{96,97}$

The phase III clinical trials, the RECORD Studies, were designed to look at the effectiveness of rivaroxaban in the prevention of VTE in patients undergoing hip or knee surgery. The RECORD I and RECORD III trials revealed higher effectiveness of rivaroxaban compared to enoxaparin in VTE prevention following orthopedic surgery, whilst the RECORD II study provided evidence that prolonged administration of rivaroxaban had additional clinical benefits compared to short-term therapy. ${ }^{98-100}$ The utility of rivaroxaban for VTE treatment was assessed in two phase II studies which showed that rivaroxaban had similar efficacy when compared with enoxaparin/warfarin in the treatment of VTE.

In the ODIXa-DVT study, the incidence of major and minor bleeding increased with escalating doses of rivaroxaban (range of $5.0 \%$ to $11.6 \%$ ) as compared with patients treated with enoxaparin/warfarin (6.3\%). ${ }^{101}$ In the EINSTEIN-DVT study, the incidence of clinically relevant bleeding occurred in $2.2 \%-6.0 \%$ of patients in rivaroxaban groups and in $8.8 \%$ of patients in heparin/warfarin group, with no significant dose response for bleeding. ${ }^{102}$ In these two studies, no dose-efficacy relationship with rivaroxaban treatment was observed. However, the dose-dependent increase in the risk of bleeding was reported in the ODIXa-DVT study indicating that a twice-daily regimen for rivaroxaban might increase risk of bleeding. Nonetheless, the results of these two studies had supported the safety and efficacy of rivaroxaban in the treatment of DVT. Based on these results, further phase III randomized trials of rivaroxaban for the treatment of DVT and for the prevention of stroke in AF (ROCKET-AF) with $20 \mathrm{mg}$ once-daily are ongoing. Rivaroxaban has been assessed by NICE, ${ }^{103}$ who have recommended it as an option for the prevention of VTE in adults having elective total hip replacement surgery or elective total knee replacement surgery. The initial dose, subject to normal hemostasis and reflective of additional risk factors, should be $10 \mathrm{mg}$ within 6-10 hours after surgery, then for two weeks in knee surgery or five weeks in major hip surgery.

Apixaban is a highly selective and potent inhibitor of factor Xa at advanced clinical development. It has a small molecular weight, with a bioavailability of more than $50 \%$ 


\section{Role of anticoagulants}

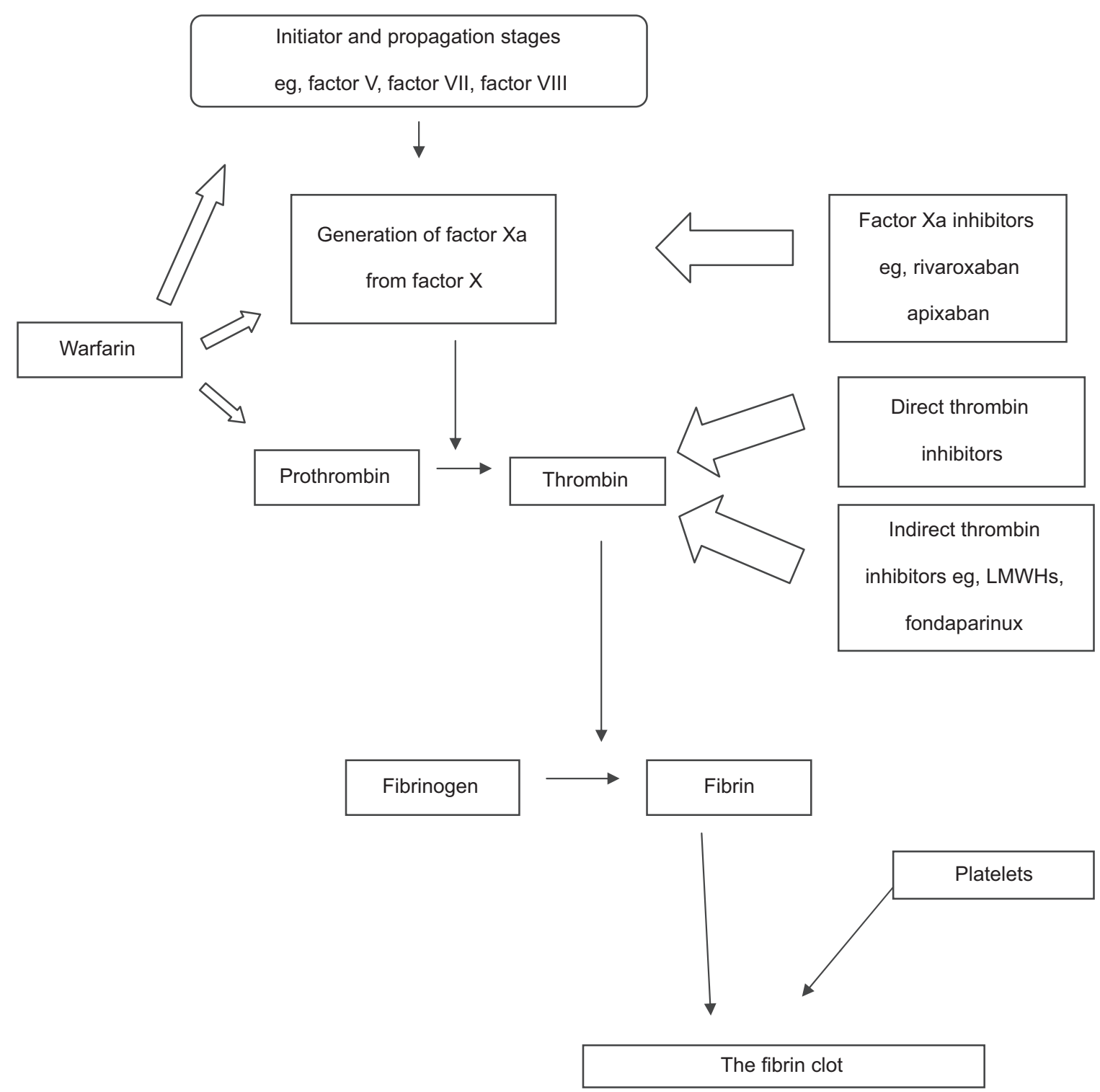

Figure I The coagulation system simplified.

Abbreviation: $\mathrm{LMWHs}$, low-molecular-weight heparins.

and half-life of between nine and 14 hours. Apixaban has fixed twice-daily dosing and is metabolized in the liver via CYP3A4, with about $25 \%$ excreted by the kidneys and the remainder by intestinal excretion. ${ }^{104}$ It has been shown to be safe and well tolerated in initial testing in volunteers and its anticoagulant effects closely correlated to plasma concentration of the drug. In the phase II APROPOS trial apixaban prevented more cases of VTE and death after total knee replacement than enoxaparin, but the risk of bleeding correlated with drug dose. ${ }^{105}$ In a relatively small BotticelliDVT trial (520 patients with acute symptomatic DVT), apixaban demonstrated effectiveness in the prevention of recurrent VTE similar to conventional therapy with LMWH followed by warfarin (target INR 2.0-3.0). The principal safety outcome (composite of major and clinically relevant, nonmajor bleeding) occurred in $7.3 \%$ of the apixaban-treated patients versus $7.9 \%$ of patients with reference treatment. ${ }^{106}$

Another direct thrombin inhibitor, betrixaban, is being trialed. It has a small molecular weight, with an oral bioavailability of $47 \%$ and half-life of 19 hours, and is eliminated via intestinal excretion. A randomized phase II clinical trial, the EXPERT study, investigated the safety and efficacy 
of betrixaban in comparison with enoxaparin for VTE prevention in patients undergoing total knee replacement surgery. More than 200 patients were randomized to either betrixaban (15 or $40 \mathrm{mg}$ twice daily) or enoxaparin (30 mg twice daily). Betrixaban demonstrated antithrombotic activity and appeared well tolerated in knee replacement patients at the doses studied. ${ }^{107}$

\section{Conclusions}

In the UK, government initiatives have pushed anticoagulation center-stage in many aspects of medical and surgical care. ${ }^{108,109}$ The vast weight of prevention and treatment of VTE falls to the management of warfarin and LMWHs, with fondaparinux gaining use. However, the last few years has seen the development of new oral anticoagulants that may take over from currently established agents, ${ }^{110}$ and for which government bodies are releasing guidelines. ${ }^{78,79,94,103}$ It seems likely that future practice will see the increasing use of novel oral anticoagulants.

\section{Disclosures}

ADB has taken hospitality, speaker fees and research funds from GlaxoSmithKline, Sanofi-Aventis and Boehringer Ingleheim. The University Department of Medicine at City Hospital recruits for anticoagulant trials.

\section{References}

1. White RH. The epidemiology of venous thromboembolism. Circulation. 2003;107(23 Suppl 1):14-18.

2. Heit JA. Venous thromboembolism: disease burden, outcomes and risk factors. J Thromb Haemost. 2005;3:1611-1617.

3. Anderson FA, Spencer FA. Risk factors for venous thromboembolism. Circulation. 2003;107:I9-I16.

4. Blann AD, Lip GYH. Venous thromboembolism, Br Med J. 2006; 332:215-219.

5. Heparin J, Hirsh Heparin. N Engl J Med. 1991;324:1565-1574.

6. Buller HR, Sohne M, Middeldorp S. Treatment of venous thromboembolism. J Thromb Haemost. 2005;3:1554-1560.

7. Turpie AG, Chin BS, Lip GY. Venous thromboembolism: pathophysiology, clinical features and prevention. Br Med J. 2002;325: 887-890.

8. Schmidt-Mulheim A. Beitrage zur Kenntnis des peptones under seiner physiologischen Bedeutung. Archiv fur Anatomie und Physiologie Physiologische Abteilung. 1880:33-56.

9. Doyon M. Rapports du foie avec la coagulation du sang. Journal de Physiologie et de Pathologie General. 1912;14:229-240.

10. McLean J. The thromboplastinics action of cephalin. Am J Physiol. 1916;41:250-257.

11. Howell WH. Heparin and anticoagulation. Am J Physiol. 1923;63: 434-435.

12. Jorpes JE. The chemistry of heparin. Biochem J. 1935;29: $1817-1830$

13. Crafoord C. Preliminary report on post-operative treatment with heparin as a preventative of thrombosis. Acta Chir Scand. 1937;79:407-426.

14. Best $\mathrm{CH}$. Preparation of heparin and its use in the first clinical case. Circulation. 1959;19:79-86.
15. Brinkhous KM, Smith HP, Warner ED, Seegers WH. The inhibition of blood clotting: an unidentified substance which acts in conjunction with heparin to prevent the conversion of prothrombin to thrombin. Am J Physiol. 1939;125:683-687.

16. Beeler D, Rosenberg R, Jordan R. Fractionation of low molecular weight heparin species and the interaction with antithrombin. $J$ Biol Chem. 1979;254:2902-2913.

17. Barrowcliffe TW, Johnson EA, Eggleton CA, Kemball-Cook G, Thorne DP. Anticoagulant activities of high and low molecular weight heparin fractions. Br J Haematol. 1979;41:573-583.

18. Kakkar VV, Djazaeri B, Fok M, Scully MF, Westwick J. Low molecular weight heparin and prevention of postoperative deep vein thrombosis. Br Med J. 1982;284:375-379.

19. Hirsh J, Ofosu F, Buchanan M. Rationale behind the development of low molecular weight heparin derivatives. Semin Thromb Haemost. 1985;11:13-16.

20. Roemisch J, Gray E, Hoffmann JN, Wiedermann CJ. Antithrombin: a new look at the actions of a serine protease inhibitor. Blood Coag Fibrinolysis. 2002;13:657-670.

21. Salzman EW, Rosenberg RD, Smith MH, Lindon JN, Favreau L. Effects of heparin and heparin fractions on platelet aggregation. J Clin Invest. 1980;65:64-73.

22. Blajchman MA, Young E, Ofusu FA. Effects of unfractionated heparin, dermatan sulphate and low molecular weight heparin on vessel wall permeability in rabbits. Ann NY Acad Sci. 1989;556:245-254.

23. Lindahl $\mathrm{U}$, Hook M. Glycosaminoglycans and their binding to biological macromolecules. Ann Rev Biochem. 1978;47:385-417.

24. Cipolle R, Seifert R, Neilan B, Zaske DE, Hasus E. Heparin kinetics: variables related to disposition and dosage. Clin Pharmacol Ther. 1981; 29:387-393.

25. Shojania AM, Tetreault J, Turnbull JL. The variations between heparin sensitivity of different lots of activated partial thromboplastin time reagent produced by the same manufacturer. Am J Clin Pathol. 1988;89:19-23.

26. Hyers TM, Agnelli G, Hull RD, et al. Antithrombotic therapy for venous thromboembolic disease. Chest. 2001;119:176S-193S.

27. Turpie AGG, Chin BSP, Lip GYH. Venous thromboembolism: treatment strategies. Br Med J. 2002;325:948-950.

28. Barritt DW, Jordan SC. Anticoagulant drugs in the treatment of pulmonary embolus: a controlled clinical trial. Lancet. 1960;1(7138): 1309-1312.

29. Kernohan RJ, Todd C. Heparin therapy in thromboembolic disease. Lancet. 1966;1(7438):621-623.

30. Salzman EW, Deykin D, Shaprio MR, Rosenberg R. Management of heparin therapy: controlled prospective trial. $N$ Engl J Med. 1975; 292:1046-1050.

31. Hull RD, Raskob GE, Hirsh J, et al. Continuous intravenous heparin compared with intermittent subcutaneous heparin in the initial treatment of proximal-vein thrombosis. N Engl J Med. 1986;315:1109-1114.

32. Brandjes DPM, Heijboer H, Buller HR, de Rijk M, Jagt H, ten Cate JW. Acenocoumarol and heparin compared with acenocoumarol alone in the initial treatment of proximal vein thrombosis. N Engl J Med. 1992; 327:1485-1489.

33. Schulman S, Rhedin AS, Lindmarker P, et al. A comparison of six weeks of oral anticoagulant therapy after a first episode of venous thromboembolism. Duration of anticoagulation trial study group. $N$ Engl J Med. 1995;332:1661-1665.

34. Turpie AG, Hirsch J. Prophylaxis and therapy of venous thromboembolism. CRC Crit Rev Clin Lab Sci. 1979;10:247-274.

35. Gallus A, Jackaman J, Tillett J, Mills W, Wycherley A. Safety and efficacy of warfarin started early after submassive proximal venous thrombosis or pulmonary embolus. Lancet. 1986;2(8519): 1293-1296.

36. Weismann RE, Tobin RW. Arterial embolism occurring during systemic heparin therapy. Arch Surg. 1958;76:219-227.

37. Chong BH. Heparin induced thrombocytopenia. J Thromb Haemost. 2003;1:1471-1478. 
38. Warkentin TE. Heparin induced thrombocytopenia. A ten year retrospective. Аnпи Rev Med. 1999;50:129-147.

39. Warkentin TE. Current agents for the treatment of patients with heparin induced thrombocytopenia. Curr Opin Pulm Med. 2002;8:405-412.

40. Xiao Z, Theroux P. Platelet activation with unfractionated heparin at therapeutic concentrations and comparisons with a low molecular weight heparin and with a direct thrombin inhibitor. Circulation. 1998;97:251-256.

41. Yusuf S, Mehta SR, Chrolavicius S, et al. Comparison of fondaparinux and enoxaparin in acute coronary syndromes. $N$ Engl $J$ Med. 2006; 354:1464-1476.

42. Warkentin TE, Levine MN, Hirsh J, et al. Heparin-induced thrombocytopenia in patients treated with low molecular weight heparin or unfractionated heparin. $N$ Engl J Med. 1995;332:1330-1335.

43. Squires JW, Pinch LW. Heparin induced spinal fractures. JAMA. 1979;241:2417-2418.

44. Sackler JP, Liu L. Heparin induced osteoporosis. Br J Radiol. 1973; 46:458-460.

45. Ginsberg JS, Kowalchuk G, Hirsch J, et al. Heparin effect on bone density. Thromb Haemost. 1990;64:286-289.

46. Edes TE, Sunderrajan EV. Heparin-induced hyperkalaemia. Arch Intern Med. 1985;145:1070-1072.

47. Dukes GE Jr, Sanders SW, Russo J Jr, et al. Transaminase elevations in patients receiving bovine or porcine heparin. Ann Intern Med. 1984; 100:646-650.

48. Hirsch J, Dalen JE, Deykin D, Poller L. Heparin: Mechanism of action, pharmacokinetics, dosing considerations, monitoring, efficacy, safety. Chest. 1992;102(Suppl):337S-351S.

49. Turpie AGG. Can we differentiate the low molecular weight heparins? Clin Cardiol. 2000;23(Suppl I):I4-I7.

50. Offord R, Perry D. Anticoagulation. London, UK: Science Press; 2002.

51. Hirsh J, Warkentin TE, Shaughnessy SG, et al. Heparin and low molecular weight heparin. Mechanism of action, pharmacokinetics, dosing, monitoring, efficacy, safety. Chest. 2001;119(Suppl):64S-94S.

52. Lensing AWA, Prins MH, Davidson BL, Hirsh J. Treatment of deep vein thrombosis with low molecular weight heparins. A meta-analysis. Arch Intern Med. 1995;155:601-607.

53. Leizorovicz A, Simonneau G, Decousus H, Boissel JP. Comparison of efficacy and safety of low molecular weight heparins and unfractionated heparin in initial treatment of deep vein thrombosis: a meta analysis. Br Med J. 1994;309:648-651.

54. Siragusa S, Cosmi B, Piovella F, Hirsch J, Ginsberg G. Low molecular weight heparins an unfractionated in the treatment of patients with acute venous thromboembolism. Results of a meta-analysis. Am J Med. 1996;100:269-277.

55. Low-molecular-weight heparin in the treatment of patients with venous thromboembolism. The Columbus Investigators. $N$ Engl J Med. 1997;337:657-662.

56. Simonneau G, Sors $\mathrm{H}$, Charbonnier B, et al; for the THESEE study group. A comparison of low molecular weight heparin with unfractionated heparin for acute pulmonary embolism. N Engl J Med. 1997;337:663-669.

57. Gould MK, Dembitzer AD, Doyle RL, et al. Low molecular weight heparins compared with unfractionated heparin for the treatment of acute deep vein thrombosis: a meta-analysis of randomised controlled trials. Ann Intern Med. 1999;130:800-809.

58. Norrby K. Heparin and angiogenesis: a low-molecular-weight fraction inhibits and a high-molecular-weight fraction stimulates angiogenesis systemically. Haemostasis. 1993;23(Suppl 1):141-149.

59. Själander A, Jansson JH, Bergqvist D, Eriksson H, Carlberg B, Svensson P. Efficacy and safety of anticoagulant prophylaxis to prevent venous thromboembolism in acutely ill medical inpatients: a metaanalysis. J Intern Med. 2008;263:52-60.

60. Levine M, Gent M, Hirsch J, et al. A comparison of low molecular weight heparin administered primarily at home with unfractionated heparin administered in the hospital for proximal deep vein thrombosis. N Engl J Med. 1996;334:677-681.
61. Koopman MMW, Prandoni P, Piovella F, et al. Treatment of venous thrombosis with intravenous unfractionated heparin administered in the hospital as compared with subcutaneous LMWH administered at home. N Engl J Med. 1996;334:682-687.

62. Omran H, Hammerstingl C, Schmidt H, von der Recke G, Paar WD, Lüderitz B. A prospective and randomised comparison off the safety and effects of therapeutic levels of enoxaparin versus unfractionated heparin in chronically anticoagulated patients undergoing elective cardiac catheterisation. Thromb Haemost. 2003;90:267-271.

63. Jackson MR, Clagett GP. Antithrombotic therapy in peripheral arterial occlusive disease. Chest. 2001;119:283S-299S.

64. Lee AY. The role of low molecular weight heparins in the prevention and treatment of venous thromboembolism in cancer patients. Curr Opin Pulm Med. 2003;9:351-355.

65. Lee AY, Levine MN, Baker RI, et al. Low-molecular-weight heparin versus a coumarin for the prevention of recurrent venous thromboembolism in patients with cancer. $N$ Engl J Med. 2003;349:146-153.

66. Khorana AA. The NCCN Clinical Practice Guidelines on Venous Thromboembolic Disease: strategies for improving VTE prophylaxis in hospitalized cancer patients. Oncologist. 2007;12:1361-1370.

67. Levine MN, Lee AY, Kakkar AK. From Trousseau to targeted therapy: New insights and innovations in thrombosis and cancer. $J$ Thromb Haemost. 2003;1:1456-1463.

68. Folsom AR, Cushman M, Tsai MY, et al. A prospective study of venous thromboembolism in relation to factor V Leiden and related factors Blood. 2002;99:2720-2725.

69. Schulman S. Unresolved issues in anticoagulant therapy. J Thromb Haemost. 2003;1:1464-1470.

70. Knight CJ, Panseart M, Wilson DJ, et al. Increased platelet responsiveness following coronary stenting. Eur Heart J. 1998;19:1239-1248.

71. The British National Formulary. Issue 57. 2009. Available from http://www.bnf.org/. Accessed March 10, 2009.

72. Turpie AG, Bauer KA, Eriksson BI, Lassen MR. Fondaparinux vs enoxaparin for the prevention of venous thromboembolism in major orthopedic surgery: a meta-analysis of 4 randomized double-blind studies. Arch Intern Med. 2002;162:1833-1840.

73. Hirsh J, Guyatt G, Albers GW, et al. Antithrombotic and thrombolytic therapy. American College of Chest Physicians. Evidence-Based Clinical Practice Guidelines (8th Edition). Chest. 2008;133(6 Suppl):71S-109S. Errata in: Chest. 2008;134:473 and Chest. 2008;134:892.

74. British Thoracic Society Standards of Care Committee Pulmonary Embolism Guideline Development Group. British Thoracic Society Standards of Care Committee Pulmonary embolism guideline. Thorax. 2003;58:470-483.

75. The Scottish Intercollegiate Guidelines Network (SIGN). Available from http://www.sign.ac.uk/. Accessed March 10, 2009.

76. Baglin T, Barrowcliffe TW, Cohen A, Greaves M. Guidelines on the use and monitoring of heparin. Br J Haematol. 2006;133:19-34.

77. Royal College of Obstetrics and Gynaecology. Guideline 28. Thromboembolic disease in pregnancy and the puerperium: Acute management. London UK: Royal College of Obstetrics and Gynaecology; 2001. Available from http://www.rcog.org.uk/. Accessed March 10, 2009.

78. Report of the Independent Expert Working Group on the prevention of venous thromboembolism in hospitalized patients. Department of Health. Available from http://www.doh.gov.uk/. Accessed March 10, 2009

79. National Institute for Health and Clinical Excellence. Guideline 46. VTE: Reducing the risk of VTE (DVT and PE) in in-patients undergoing surgery. 2008. Available from http://www.nice.org.uk/. Accessed March 10, 2009.

80. Tan KT, Lip GY. Fondaparinux. Curr Pharm Des. 2005;11:415-419.

81. Gross PL, Weitz JI. New anticoagulants for treatment of venous thromboembolism. Arterioscler Thromb Vasc Biol. 2008;28:380-386.

82. Crowther MA, Warkentin TE. Bleeding risk and the management of bleeding complications in patients undergoing anticoagulant therapy: focus on new anticoagulant agents. Blood. 2008;111: $4871-4879$. 
83. Hirsh J, O’Donnell M, Eikelboom JW. Beyond unfractionated heparin and warfarin. Circulation. 2007;116:552-560.

84. Khoo CW, Tay KH, Shantsila E, Lip GYH. Novel oral anticoagulants. Int J Clin Pract. 2009;63:630-641.

85. Shantsila E, Lip GY. Apixaban, an oral, direct inhibitor of activated Factor Xa. Curr Opin Investig Drugs. 2008;9:1020-1033.

86. Kakar P, Watson T, Lip GY. Rivaroxaban. Drugs Today. 2007;43: 129-136.

87. Stangier J, Rathgen K, Stahle H, Gansser D, Roth W. The pharmacokinetics, pharmacodynamics and tolerability of dabigatran etexilate, a new oral direct thrombin inhibitor, in healthy male subjects. Br J Clin Pharmacol. 2007;64:292-303.

88. Eriksson BI, Dahl OE, Ahnfelt L, et al. Dose escalating safety study of a new oral direct thrombin inhibitor, dabigatran etexilate, in patients undergoing total hip replacement: BISTRO I. J Thromb Haemost. 2004;2:1573-1580.

89. Eriksson BI, Dahl OE, Buller HR, et al; BISTRO II Study Group. A new oral direct thrombin inhibitor, dabigatran etexilate, compared with enoxaparin for prevention of thromboembolic events following total hip or knee replacement: The BISTRO II randomized trial. J Thromb Haemost. 2005;3:103-111.

90. Ezekowitz MD, Reilly PA, Nehmiz G, et al. Dabigatran with or without concomitant aspirin compared with warfarin alone in patients with nonvalvular atrial fibrillation (PETRO Study). Am J Cardiol. 2007;100:1419-1426.

91. Eriksson BI, Dahl OE, Rosencher N, et al; RE-NOVATE Study Group. Dabigatran etexilate versus enoxaparin for prevention of venous thromboembolism after total hip replacement: a randomized, double-blind, non-inferiority trial. Lancet. 2007;370:949-956.

92. Eriksson BI, Dahl OE, Rosencher N, et al; RE-MODEL Study Group. Oral dabigatran etexilate vs. subcutaneous enoxaparin for the prevention of venous thromboembolism after total knee replacement: the RE-MODEL randomized trial. J Thromb Haemost. 2007;5: 2178-2185.

93. Ginsberg JS, Davidson BL, et al. RE-MOBILIZE Writing Committee. Oral thrombin inhibitor dabigatran etexilate vs North American enoxaparin regimen for prevention of venous thromboembolism after knee arthroplasty surgery. 2009;24(1):1-9.

94. National Institute for Health and Clinical Excellence. Final appraisal determination. Dabigatran etexilate for the prevention of VTE after hip or knee replacement surgery in adults. 2008. Available from http://www. nice.org.uk/. Accessed March 10, 2009.

95. Eikleboom JE, Weitz JI. Dabigatran etexilate for prevention of venous thromboembolism. Thromb Haemost. 2009;101:doi:10.1160/ TH08-10-0708.

96. Kubitza D, Becka M, Voith B, Zuehlsdorf M, Wensing G. Safety, pharmacodynamics, and pharmacokinetics of single doses of BAY59-7939, an oral, direct factor Xa inhibitor. Clin Pharmacol Ther. 2005; $78: 412-421$.

97. Perzborn E, Strassburger J, Wilmen A, et al. In vitro and in vivo studies of the novel antithrombotic agent BAY 59-7939 - an oral, direct factor Xa inhibitor. J Thromb Haemost. 2005;3:514-521.
98. Eriksson BI, Borris LC, Friedman RJ, et al; RECORD1 Study Group. Rivaroxaban versus enoxaparin for thromboprophylaxis after hip arthroplasty. N Engl J Med. 2008;358:2765-2775.

99. Kakkar AK, Brenner B, Dahl OE, et al; RECORD2 Investigators. Extended duration rivaroxaban versus short-term enoxaparin for the prevention of venous thromboembolism after total hip arthroplasty: a double-blind, randomised controlled study. Lancet. 2008;371(9632):31-39.

100. Lassen MR, Ageno W, Borris LC, et al; RECORD3 Investigators. Rivaroxaban versus enoxaparin for thromboprophylaxis after total knee arthroplasty. N Engl J Med. 2008;358:2776-2786.

101. Agnelli G, Gallus A, Goldhaber SZ, et al; the ODIXa-DVT Study Investigators. Treatment of proximal deep-vein thrombosis with the oral direct factor Xa inhibitor rivaroxaban (BAY 59-7939): the ODIXa-DVT study. Circulation. 2007;116:180-187.

102. Buller HR, Lensing AWA, Prins MH, et al; the Einstein-DVT Dose-Ranging Study Investigators. A dose-ranging study evaluating once-daily oral administration of the factor Xa inhibitor rivaroxaban in the treatment of patients with acute symptomatic deep vein thrombosis: the Einstein-DVT Dose-Ranging Study. Blood. 2008; 112:2242-2247.

103. National Institute for Health and Clinical Excellence. Final appraisal determination. Rivaroxaban for the prevention of VTE after hip or knee replacement in adults. March 5, 2009. Available from http://www.nice. org.uk/guidance/index.jsp?action $=$ download $\& 0=43417$. Accessed March 10, 2009.

104. Wong PC, Crain EJ, Xin B, et al. Apixaban, an oral, direct and highly selective factor Xa inhibitor: in vitro, antithrombotic and antihemostatic studies. J Thromb Haemost. 2008;6:820-829.

105. Lassen MR, Davidson BL, Gallus A, Pineo G, Ansell J, Deitchman D. The efficacy and safety of apixaban, an oral, direct factor Xa inhibitor, as thromboprophylaxis in patients following total knee replacement. J Thromb Haemost. 2007;5:2368-2375.

106. Buller H, Deitchman D, Prins M, Segers A; Botticelli Investigators. Efficacy and safety of the oral direct factor Xa inhibitor apixaban for symptomatic deep vein thrombosis. The Botticelli DVT dose-ranging study. J Thromb Haemost. 2008;6:1313-1318.

107. Turpie AG, Bauer KA, Davidson BL, et al; EXPERT Study Group. A randomized evaluation of betrixaban, an oral factor Xa inhibitor, for prevention of thromboembolic events after total knee replacement (EXPERT). Thromb Haemost. 2009;101:68-76.

108. National Patients Safety Agency. Patient Safety Alert 18. Actions that can make anticoagulant therapy safer. 2008. Available from: http://www.npsa.nhs.uk/health/alerts. Accessed March 15, 2009.

109. Department of Health. The VTE Implementation Working Group. September 18, 2008. Available from: http://www.dh.gov.uk/en/ Publichealth/Healthprotection/Bloodsafety/DH_082132.

110. Weitz JI, Hirsh J, Samama MM; American College of Chest Physicians. New antithrombotic drugs: American College of Chest Physicians Evidence-Based. Clinical Practice Guidelines (8th Edition). Chest. 2008;133(6 Suppl):234S-256S. Erratum in Chest. 2008;134:473.
Vascular Health and Risk Management

\section{Publish your work in this journal}

Vascular Health and Risk Management is an international, peerreviewed journal of therapeutics and risk management, focusing on concise rapid reporting of clinical studies on the processes involved in the maintenance of vascular health; the monitoring, prevention and treatment of vascular disease and its sequelae; and the involvement of

\section{Dovepress}

metabolic disorders, particularly diabetes. This journal is indexed on PubMed Central and MedLine. The manuscript management system is completely online and includes a very quick and fair peer-review system, which is all easy to use. Visit http://www.dovepress.com/ testimonials.php to read real quotes from published authors. 